\title{
Sub-surface characterization of the Amphiteatrum Flavium area (Rome, Italy) through single-station ambient vibration measurements
}

\author{
Salomon Hailemikael ${ }^{1,}$, Giuliano Milana², Fabrizio Cara ${ }^{2}$, Maurizio Vassallo ${ }^{3}$, \\ Marta Pischiutta ${ }^{2}$, Sara Amoroso ${ }^{3}$, Paola Bordoni ${ }^{2}$, Luciana Cantore ${ }^{2}$, Giuseppe Di Giulioº \\ Deborah Di Naccio ${ }^{2}$, Daniela Famiani ${ }^{2}$, Alessia Mercuri ${ }^{2}$
}

\footnotetext{
${ }^{1}$ Agenzia nazionale per le nuove tecnologie, l'energia e lo sviluppo economico sostenibile, C.R. Casaccia, Rome, Italy

2 Istituto Nazionale di Geofisica e Vulcanologia, Sezione Roma1, Rome, Italy

3 Istituto Nazionale di Geofisica e Vulcanologia, Sezione Roma1, L'Aquila, Italy
}

\author{
Article history \\ Received January 17, 2017; accepted May 16, 2017.
}

Subject classification:

Waves and wave analysis, Surveys, Measurements and monitoring, Seismic risk, Exploration Geophysics, Seismic methods.

\begin{abstract}
The Amphiteatrum Flavium in Rome (Italy) is one of the most known monument in the world. With the aim of understanding the seismic response of the area where the Amphiteatrum Flavium is built and investigating possible soil-structure interactions, we performed a seismic experiment in 2014, based on ambient vibration (AMV) recordings. The measurements were performed at the original ground level, on the foundation and at different floors of the monument. Data were analyzed in terms of standard Fourier analysis (FAS) and horizontal-to-vertical spectral ratio technique $(H / V)$. Moreover, we performed an active $P$-wave seismic tomography analysis of the foundation materials to better understand their influence on the recorded signals. Our results point out that there is a strong temporal and spatial stability of the H/V curves, suggesting a uniform seismic response at the monument site. Conversely, spectral amplitudes of AMV show relevant temporal and spatial variability at the investigated site, due to the daily variations of AMV levels and to the low-pass filtering effect of the stiff Amphiteatrum Flavium foundation that strongly attenuates the signals for frequencies above $4 \mathrm{~Hz}$, i.e. those mostly originated by traffic vibrations. Moreover, we observe that the main vibration frequencies of the super-structure are not present as energetic peaks in the spectra of the ground-motion recorded at its base.
\end{abstract}

\section{Introduction}

The Amphitheatrum Flavium (hereinafter AF), commonly known as the Colosseum, probably represents the most important heritage of the Roman Empire in Rome (Italy). With more than 6 millions of tickets sold every year, it is the most visited monument in Italy and the second in the world, after the Great Chinese Wall. Such cultural and economical resource needs to be preserved and protected by any potential cause of degradation.

The building dates from the first century a.C. and during its life it suffered many damages. Since the decline of the Roman Empire, the ancient city and its main monuments managed to withstand the frequent barbaric invasions, with fires and devastations. In the 500 a.C. it was used as burial area, few years later as a castle. In the 1200 a.C. it was occupied by the Frangipane palace, later destroyed, but some building still remained there. For years and also during the Italian Renaissance, the AF was subjected of material looting (marble, travertine, etc.), used to erect and decorate new buildings (e.g. Barberini Palace, Ripetta's harbour). It is not incorrect to say that the AF became one of the most exploited quarries during the Renaissance [Lanciani 1897]. Moreover, during time the monument was used as granary, and the external area of the AF was used both for poor buildings directly leaned against the monument and as breeding area.

A first restoration work of the AF was ordered by Pope Benedetto XIV around 1750. Later, another restoration work of the roman monument started at the beginning of 1800 under Pope Pio VII with architect Raffaele Stern, who tried to contrast the collapse 
of the third ring of the eastern part, triggered by a strong earthquake occurred in 1806. In 1823 architect Giuseppe Valadier designed and made a restoration work in the western part of the AF, toward the Roman Forum.

Nowadays, the monument and its surroundings area have been completely recovered. Nevertheless, the AF is inserted in a modern urban context producing high-levels of vibrations, mostly due to buses, cars and subway trains, that run just few meters apart from the foundation (Figure 1). These traffic-induced vibrations represent a potential new risk of degradation for the AF.

In such context, the role of earthquakes in the

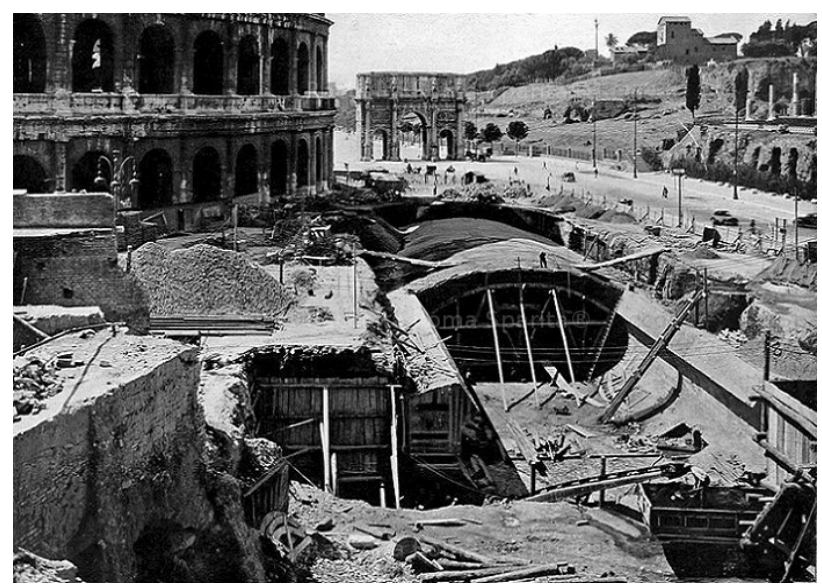

Figure 1. Picture showing the works for the construction of the underground B line around 1940.

(https: / / www.romasparita.eu/ foto-roma-sparita/96998).

damage of AF has been debated since long time [a complete review can be found in Molin et al. 1995 and Galli and Molin 2014]. In fact, even though the rate and the level of seismicity for Rome is low (Is $<8$ MCS) and mainly due to the seismogenic sources located in the Apennines (distance $90 \div 130 \mathrm{~km}$ ) and the area of the Albani hills Volcano $(10 \div 20 \mathrm{~km})$, the historical literature reports that Rome severely felt the earthquakes occurred in 443 a.C, 484-508 a.C, 1349, and 1703. However, the description of the damage occurred at the AF after these events was likely exaggerated because of the prior state of the building that surely contributed to the partial collapse of the structure [Rea 1993, 1999]. Galli and Molin [2014] state that the partial collapse of the southern external ring of the AF occurred after the 1349 earthquake.

In order to give possible explanations of such level of damage, several authors investigated the role of site effects due to the local geologic conditions at the monument site [Moczo et al. 1995, Funiciello and Rovelli 1998, Pagliaroli et al. 2014a]. In particular, these authors observed that the southern part of the AF is more damaged than the northern part. Through simulations of wave propagation they pointed out that this differential damage could be caused by the different geological conditions under the two parts. In fact, the southern part lies on a former river valley filled with soft alluvial deposits, whereas the northern part is founded over older and more compact alluvial materials (Figures 2 and 3). Even though numerical simulations are able to describe the soil response, they do not take into account the role of the AF rigid foundation that can behave as a filter on the seismic signals. Moreover, literature lacks of an exhaustive collection of real data to support or contrast this hypothesis.

Therefore the main goal of this study is to contribute to fill this gap. We have performed and analyzed several long lasting ambient vibration (hereinafter AMV) measurements inside the AF with the following aims:

i) investigating the spectral characteristics of vibrations induced by natural and anthropic sources;

ii) exploring the effect of the building foundation on the spectral characteristics of AMV;

iii) checking the temporal and spatial variation of AMV possibly correlating it with the sub-surface shear-wave velocity structure and the geometry of the monument foundation as well as the properties of the foundation materials.

In order to better understand the influence of AF foundation on the recorded ground motion we also performed an active P-wave seismic tomography of the foundation materials.

\section{Geological setting}

The AF is located just few meters apart from the ancient Forum of Rome. Figure 3 shows a detailed geological cross-section below the AF, modified after Pagliaroli et al. [2014a]. The studied area lies inside the Tiber River sedimentary basin, which is characterized by a complex stratigraphic pattern [Milli 1997, Funiciello and Giordano 2008].

The geologic bedrock is represented by the Monte Vaticano Formation (MVA) composed of Pliocene marine overconsolidated clays and marly clays [Funiciello and Parotto 1978] with thickness up to $900 \mathrm{~m}$ [Pagliaroli et al. 2014a] which have been traditionally considered as the seismic bedrock in the area of Rome [Rovelli et al. 1994, Bonilla et al. 2011]. The MVA unit is overlain by Lower Pleistocene shallow marine sediments and by a layered volcano-sedimentary succession of Early Pleistocene-Late Pleistocene age. The formers include Santa Cecilia (CIL) and Valle Giulia 

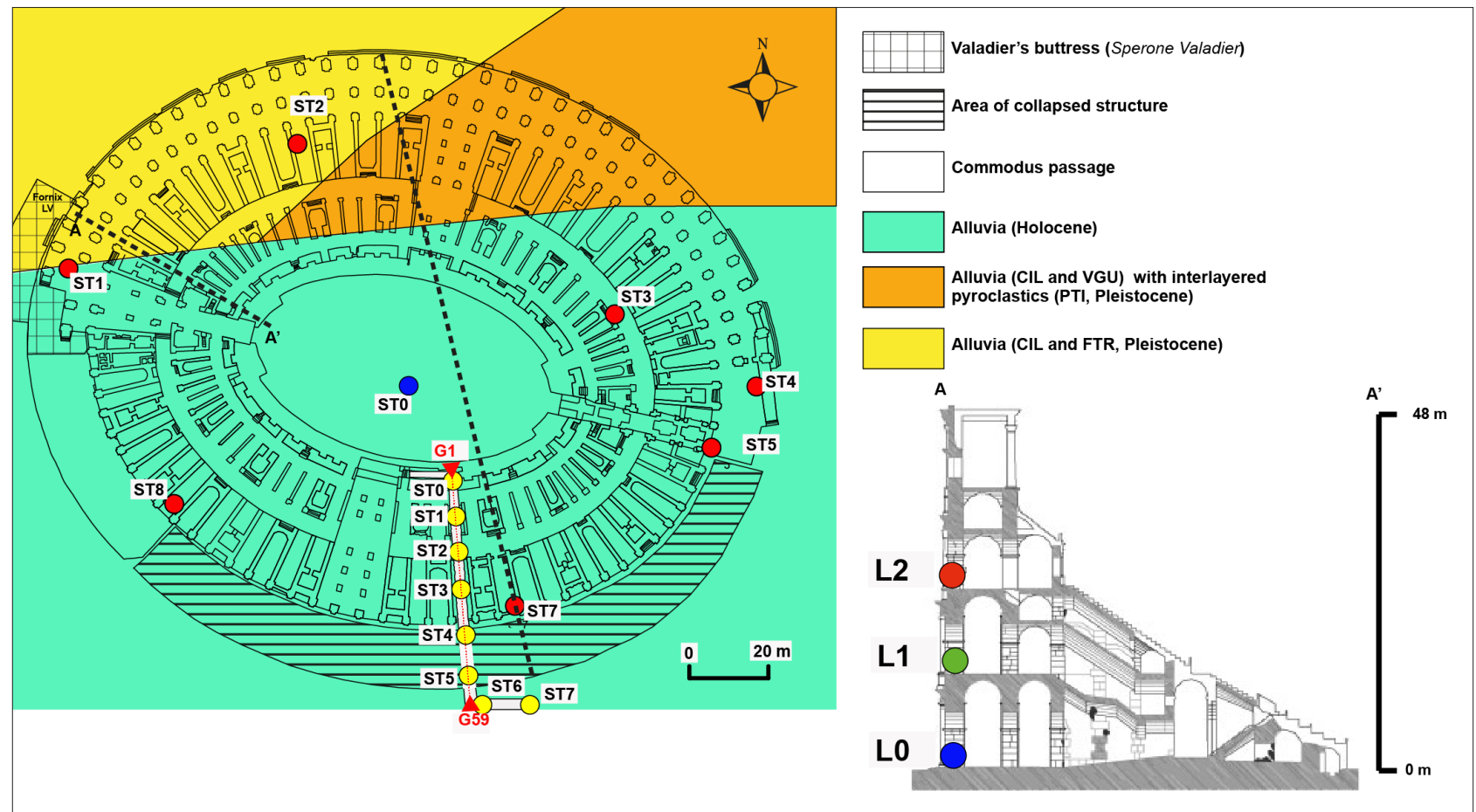

Figure 2. Geologic map (left) of the Colosseum area [redrawn after Mancini et al. 2014] and radial section (right) of the Colosseum [modified after Pau and Vestroni 2008]. In the map the area once occupied by the south external sector of the monument (dashed area) and the trace of the Commodus Passage are also shown (white area). The trace of the cross section in Figure 3 is represented as a dashed line. The locations of measurement points are represented by the colored dots (red and blue for the C-B configuration and yellow for the C-C configuration, left panel). In the right panel is shown a section of the monument (dashed line A-A' at Fornix LV) with the position of the sensors in the C-D configuration (colored dots, the colors refer to the H/V curves in Figure 10). The positions of the first (G1) and last (G59) geophones of the seismic tomography linear array are also shown as red triangles.

(VGU) sedimentary formations [Giordano and Mazza 2010 and references therein]. Volcano-sedimentary succession was originated from the Sabatini and Albani hills volcanic complexes and include both volcanoclastic inter-layered fluvio-lacustrine sediments, lava flows and distal pyroclastic deposits [Giordano and Mazza 2010], as Palatino Unit (PTI), Fosso del
Torrino (FTR) and Villa Senni Formations (VSN1).

This volcano-sedimentary succession was carved and refilled by the Tiber River and its former tributaries during the Plio-Pleistocene eustatic variations of the sea level. The AF mainly lies on the former Labicano river valley, one of these tributaries. This river valley is filled by Holocene alluvia belonging to

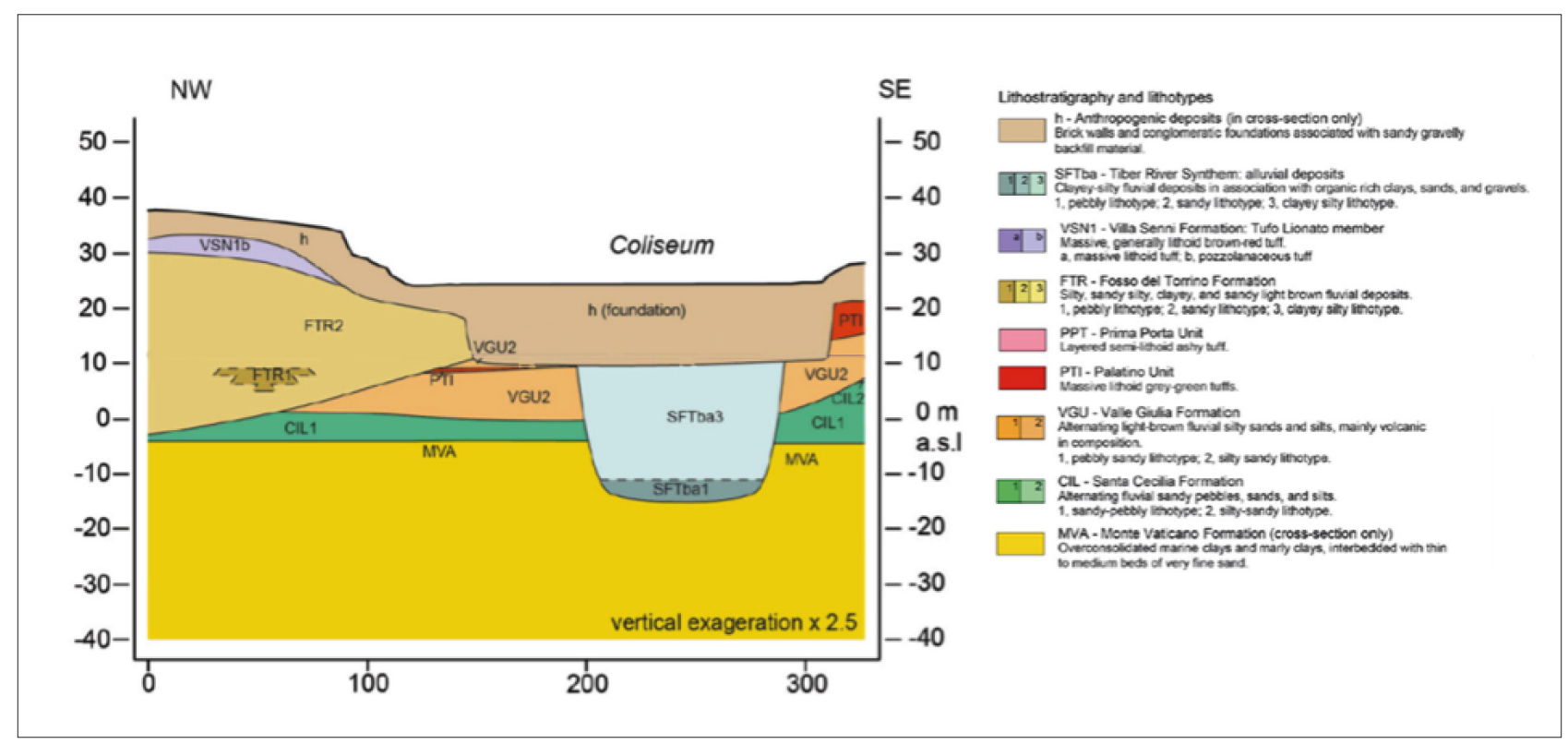

Figure 3. Detailed geological cross-section below the AF [modified after Pagliaroli et al. 2014a]. 
the Tiber River Synthem [SFTba unit, e.g. Bozzano et al. 2000, Marra et al. 2008, Raspa et al. 2008] directly overlying the MVA.

The whole surface of the city of Rome is also covered by anthropogenic deposits (h) with variable thickness. They represent a continuous cover of backfill material and building debris from the Roman age [Ciotoli et al. 2011].

The monument foundation directly lies on the geologic units described in the following. In the southern sector, the AF foundation rests on $25 \mathrm{~m}$ thick sediments belonging to SFTba. These deposits are represented by: i) a basal layer of pebble few meters thick (SFTba1) passing upward to ii) a thick layer (up to $20 \mathrm{~m}$ ) of organic-rich clay and silt (SFTba3) containing scattered peats and lenses of sands. They directly overlie the MVA unit. In the north-western side, the monument stands over $40 \mathrm{~m}$ thick fining upward sequence of sandy gravels (10 $\mathrm{m}$ thickness) passing to sandy deposits and blue clayey silt (FTR), on the MVA. Finally, in the north-eastern side the structure was built on a reduced volcano-sedimentary sequence with maximum thickness of $15 \mathrm{~m}$ and characterized by the prevalence of silty sands (VGU) with interlayered pyroclastics (PTI).

Information regarding the stiffness of these units can be found in recent papers by Pagliaroli et al. [2014b] and Cardarelli et al. [2017 - this issue]. These authors analyzed geotechnical and geophysical data obtained through in-situ and laboratory measurements. Pagliaroli et al [2014b] estimated an average value for S-wave velocity (Vs) of about $500 \mathrm{~m} / \mathrm{s}$ for the MVA, at least in the uppermost 20 meters, and values lower than $300 \mathrm{~m} / \mathrm{s}$ for the more recent sediments (sands of SFTba3). Vs values between 600 and $700 \mathrm{~m} / \mathrm{s}$ were measured for the gravel and pebble basal alluvial layer (SFTba1), determining a local moderate impedance contrast with the overlying finer alluvial sediments as well as a shear-wave velocity inversion between SFTba1 and the MVA. Furthermore, the same authors observed that there is a small difference between the Vs values pertaining to the older (FTR, Vs between $300-400 \mathrm{~m} / \mathrm{s}$ ) and the more recent alluvial sands and silts (SFTba3, Vs between 250 and $300 \mathrm{~m} / \mathrm{s}$ ). Cardarelli et al. [2017 - this issue] performed down-hole and cross-hole tests to a depth of about $40 \mathrm{~m}$ in the AF area, therefore estimating Vp and Vs values of the SFTba1-3 and MVA units. They found almost constant Vs values in the SFTba3 unit between $250-300 \mathrm{~m} / \mathrm{s}$, in agreement with the previous authors, while slightly larger values were measured for the SFTba1, Vs around $700 \mathrm{~m} / \mathrm{s}$, and for the MVA units, Vs around $600 \mathrm{~m} / \mathrm{s}$.

\section{Monument description}

The AF was built between 72 and 82 a. C. on the order of the emperors Vespasian and Titus and finally completed under the empire of Domitian. All these emperors came from the Flavium dynasty or Gens Flavia in latin, then the name given to the Amphitheatrum. The monument has an elliptical shape with external major and minor axes length of about 190 and $156 \mathrm{~m}$ respectively (Figure 2 ) and served as the major roman arena for gladiator and hunting games. The major axes is NW-SE oriented, striking about $\mathrm{N} 110^{\circ} \mathrm{E}$.

The area selected for building the AF was a valley between Velia, Oppio and Celio hills, where an artificial lake was made under emperor Nero. The lake was later drained under emperor Vespasian for building the AF.

Although few historical information are available, the foundation is supposed to be an enormous elliptical ring filled with roman concrete (opus caementicium in latin, lime with sand or pozzolanic material and mixed with stones). The estimated thickness is of about $12-13 \mathrm{~m}$ to bear the weight of the edifice and the audience. The ring has an extension of about 50-60 $\mathrm{m}$ from outside to inside, whereas the central part (hypogeum), below the arena, is on the original ground and it was divided in several service areas by walls of bricks (opus latericium in latin). These cellars are still visible and they were used for hosting games equipment, weapons and animal cages. The ground surface at the cellars is about - $6 \mathrm{~m}$ below the actual planking level. The Commodus Passage represents the best indication on how the foundation was made [Orlando er al. 2017 - this issue]. This is a corridor dug into the foundations and connecting the cellars with the outside, it was used by the Emperor and his entourage to access to the monument. Here, in the floor it is clearly visible the Roman concrete while two walls of tuff have been inserted laterally (Figure 4).

The structure of the AF is of masonry made of blocks of travertine and bricks and blocks of tuff. Its structural plan is based on a series of radial walls connected by concentric annular walls and by inclined concrete vaults [Pau and Vestroni 2008]. The building has four levels for a total height of $50 \mathrm{~m}$ above the actual ground surface. A major characteristic of the building is the presence of 80 archways or fornices (single fornix) used as entrances: 76 entrances were numbered and intended for the public, whereas four of them, located at the ends of the ellipse's axes, were used by the nobles and considered as restricted access zones. As already mentioned, the southern part of the external wall of the edifice collapsed and 


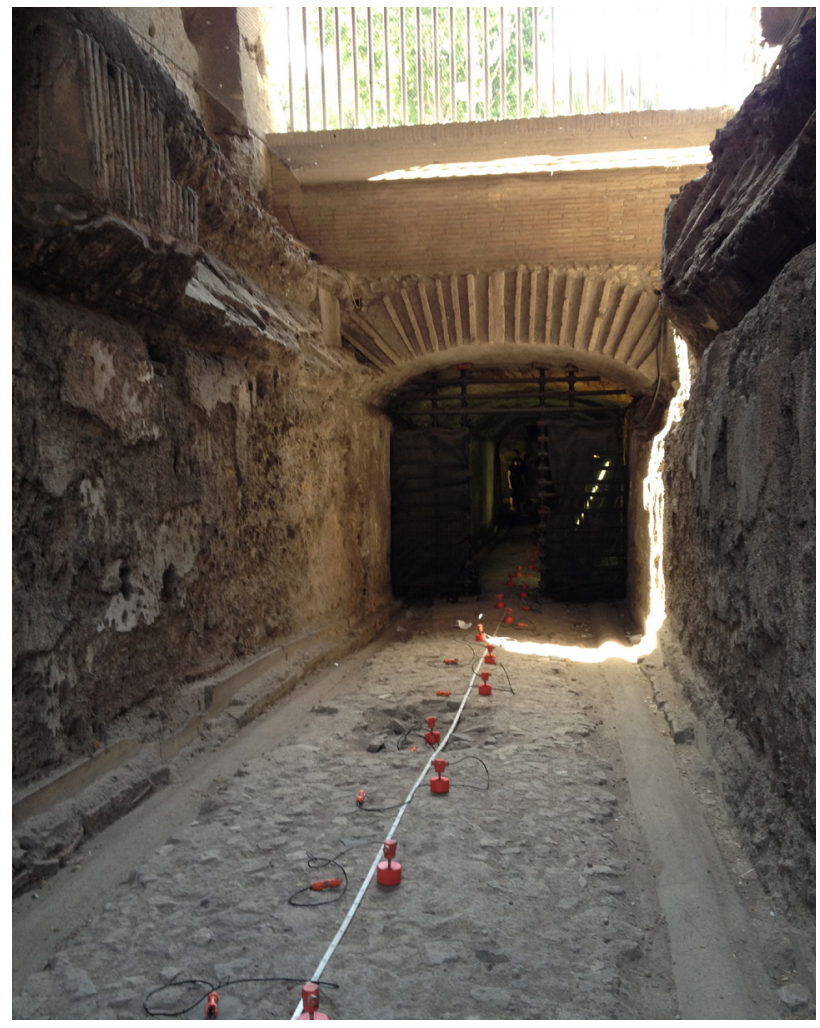

Figure 4. Picture of the Commodus Passage with the geophones installed for the active seismic experiment.

two reinforcement buttresses were built on the eastern [Sperone Stern 1805-07] and on the western side [Sperone Valadier 1823-1827], respectively.

Several authors have analyzed the dynamic characteristics of the monument both through experimental dynamic analysis and numerical simulations. $\mathrm{Pau}$ and Vestroni [2008] analyzed the response of the monument finding a main resonance frequency of the structure at $1.3 \mathrm{~Hz}$ and other resonance frequencies in the range 1-2 Hz. They also found that the mode shapes related to these frequencies mainly involve the external wall that has prevalent motion along the radial direction with respect to the monument elliptical plan and that local bending modes interest the two buttresses. Clemente et al. [2015] analyzed AMV data recorded in 1993 and recently in 2014 pointing out that resonance frequencies related to modal shapes of the structure are observed in the frequency range $1-3 \mathrm{~Hz}$ range and that the dynamic behavior of the AF is quite complex.

\section{Data acquisition, analysis and results}

\subsection{AMV Data acquisition}

We have performed several long-lasting measurements of ambient vibration in the AF, on June 24 and 25 2014. We used 8 three-components Lennartz Le3D seismic sensors with natural period of $5 \mathrm{~s}$ connected to RefTEK 130 24-bit recorders. We have deployed seismic instruments with three different configurations. The sampling rate was fixed to $250 \mathrm{sps}$, and time alignment of samples was guaranteed by GPS synchronization.

In the first configuration (C-B), 7 sensors were deployed at the present ground level directly on the foundation of the monument (red dots in Figure 2, left panel) and 1 sensor was installed at the center of the AF at the hypogeum level, the lowermost level that can be visited by tourists, about $6 \mathrm{~m}$ below the present ground level (blue dot in Figure 2, left panel). This last sensor (station code ST0) was kept in operation during all day 1 . According to the most recent subsurface geological model of the AF area [Mancini et al. 2014], the ST2 station was the only installed outside the recent alluvial deposits of the Labicano river (Figure 2, left panel).

In the second configuration (C-C), the 8 tri-axial sensors were deployed along an almost linear alignment inside the Commodus Passage. This gallery is oriented in radial direction with respect to the foundation, except for the last 20 meters that are oriented towards the East direction (Figure 2 left panel). The sensors were placed with inter-distance of about $10 \mathrm{~m}$ along the passage. In this configuration, the first 6 sensors were deployed on the top of the foundation, whereas the last two sensors were likely placed outside the foundation (yellow dots in Figure 2, left panel). The instrumentation acquired seismic signals from 16:26 PM of June 24 to 08:29: AM of June 25, allowing to assess variations of AMV during day and night hours. For both C-B and C-C configurations, the horizontal components of seismic sensors were oriented toward geographic North and East.

In the third configuration (C-D), 3 instruments were deployed along a vertical alignment at the "Fornix LV" close to the "Sperone Valadier". In this configuration, the sensors were oriented along the radial and tangential directions respect to the main axes of the AF. The scope of this deployment was to evaluate variations of AMV levels with the height of the structure, as the sensors were installed at the ground level (L0), at the first (L1) and second floors (L2) of the monument (Figure 2, right panel). With this deployment it is possible to verify the influence of the structure on the motion recorded at the foundation.

For each configuration, we extracted simultaneous time window recordings between sensors (Table 1). The collected traces were preliminarily de-trended and corrected for the instrument response. 


\begin{tabular}{|c|c|c|c|c|c|}
\hline Configuration & Day & Start time & Day & End time & Duration \\
\hline C-B & $24 / 06 / 2014$ & $08: 20$ & $24 / 06 / 2014$ & 09:30 & $01 \mathrm{~h} 10 \mathrm{~m}$ \\
\hline C-C & $24 / 06 / 2014$ & $16: 26$ & $25 / 06 / 2014$ & 08:29 & $15 \mathrm{~h} 3 \mathrm{~m}$ \\
\hline C-D & $25 / 06 / 2014$ & $07: 33$ & $25 / 06 / 2014$ & 13:08 & $05 \mathrm{~h} 35 \mathrm{~m}$ \\
\hline
\end{tabular}

Table 1. Time windows used for the analysis.

\subsection{Vp-tomography data acquisition}

With the aim to reconstruct a Vp seismic image of the foundation of the monument, we performed an active seismic experiment along the Commodus Passage. We used a linear array of 59 vertical geophones (eigen-frequency of $4.5 \mathrm{~Hz}$ ) connected by three multi-channel stations. The inter-distance among geophones was set to $1 \mathrm{~m}$ for a length of $58 \mathrm{~m}$ (Figure 2) and we used a $5 \mathrm{~kg}$ sledge-hammer as active source performing shots at different offset. In order to prevent the damaging of the roman floor, the hammer was striking on an iron plate in contact with the ground and the geophones, placed on the floor, were fixed in special cylindrical bases (Figure 4). The source was moved along the line of receivers using an interval of $2 \mathrm{~m}$, by positioning the iron plate at an intermediate distance between the geophones deployed along the line. To increase the signal-to-noise ratio during data acquisition, for each source point the seismic acquisition was repeated three times and the acquired data were stacked during the data processing.

\subsection{AMV Spectral analysis method}

The AMV recordings were analyzed through the Fourier Amplitude Spectra (FAS) and horizontal-to-vertical spectral ratio $(\mathrm{H} / \mathrm{V})$ techniques. The first method gives the spectral content of the three-component of the ground motion, allowing comparisons between analogue components recorded in different sites or in different periods of time (e.g. night and daytime). On the other hand, the $\mathrm{H} / \mathrm{V}$ technique is widely used to estimate the fundamental resonance frequency of the subsoil structure. It is particularly effective in the $1 \mathrm{D}$ approximation for the site geological structure (i.e. unique layer with low shear-wave velocity above a stiffer layer considered as the seismic bedrock). The higher is the impedance contrast (difference in shear wave velocity and density between the two layers), the more precise is the $\mathrm{H} / \mathrm{V}$ technique in retrieving the resonance effect from AMV recordings.
Constraining the fundamental resonance frequency with other independent information, the $\mathrm{H} / \mathrm{V}$ technique allows evaluating the shear wave velocity (Vs) of the first layer or the depth of the seismic bedrock [e.g. Nogoshi and Igarashi 1971, Nakamura 2000, Bard and SESAME Team 2005, Bonnefoy-Claudet, Cotton and Bard 2006]. Rarely, this method has been used also to evaluate the resonance frequencies of buildings, comparing the $\mathrm{H} / \mathrm{V}$ from recordings obtained at different floors of the building [Gallipoli et al. 2004, Facke et al. 2006, Michel et al. 2006].

To calculate both FAS and H/V curves we used the software Geopsy [Wathelet et al. 2005]. To select the most stationary parts of the signal we have applied an anti-trigger algorithm to automatically exclude time-windows affected by strong transients generated by cultural activity. We chose a length of $45 \mathrm{~s}$ to have a reasonable resolution of FAS in the low frequencies part $(<1 \mathrm{~Hz})$ of the signal. The selected time windows were further detrended and tapered at both ends using a cosine function. FAS were calculated in the frequency band $0.2-20 \mathrm{~Hz}$ and smoothed using the Konno-Ohmachi logarithmic algorithm with $b$ value of 40 [Konno and Ohmachi 1998]. The H/V spectral ratios for each window were calculated combining the horizontal FAS (geometric mean) and dividing by the vertical FAS. The final results (for both FAS and $\mathrm{H} / \mathrm{V}$ ) were obtained by averaging the single results coming from several tens of windows.

For C-B and C-D configurations, the H/V spectral ratios were also calculated rotating the horizontal components by steps of $10^{\circ}$ from north clockwise for $\mathrm{C}-\mathrm{B}$ and of $30^{\circ}$ from radial to tangential for $\mathrm{C}-\mathrm{D}$, obtaining the directional variation of $\mathrm{H} / \mathrm{V}$. This technique was firstly applied using earthquake records by Spudich et al. [1996] and was subsequently exploited by several authors [e.g. Di Giulio et al. 2009, Pischiutta et al. 2013] using ambient noise in different areas. Only for C-C, FAS and $\mathrm{H} / \mathrm{V}$ functions were calculated separating the signals recorded during day and night time. 


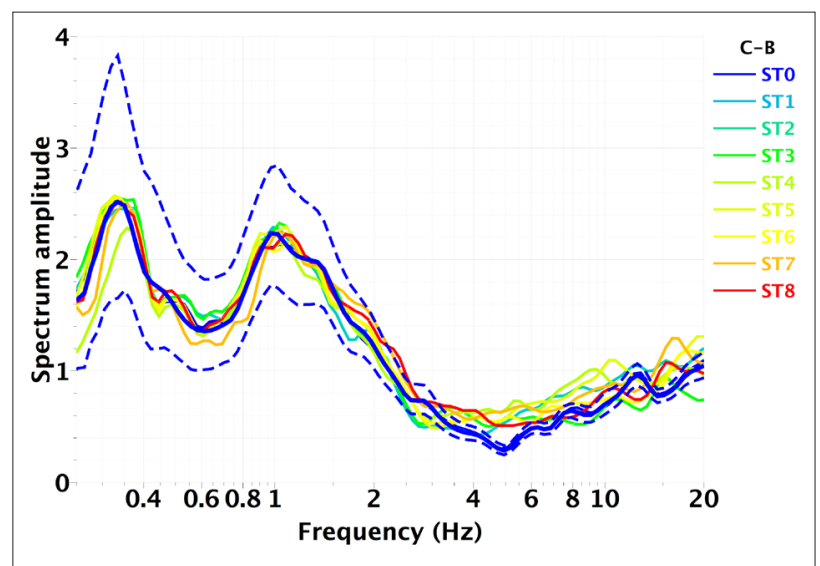

Figure 5. H/V spectral ratios calculated for the stations of C-B. The dotted lines represent the average $\mathrm{H} / \mathrm{V}$ curve \pm 1 st. dev. calculated for the ST0 measuring site.

\subsection{AMV Results}

\section{C-B configuration}

Figure 5 shows the average $\mathrm{H} / \mathrm{V}$ curves for the eight stations used in configuration C-B. The general shape of $\mathrm{H} / \mathrm{V}$ spectral ratios is similar at the measuring sites even though there are negligible differences (within one standard deviation) below $3 \mathrm{~Hz}$.

The average $\mathrm{H} / \mathrm{V}$ spectral ratios show two main peaks centered at about $0.3 \mathrm{~Hz}$ and $1.0 \mathrm{~Hz}$ with amplitude of about 2.2-2.5, respectively. The amplitude of the $\mathrm{H} / \mathrm{V}$ functions remains lower than 1 in the frequency band between 2.5 and 10-15 $\mathrm{Hz}$.

In Figure 6 we show the H/V spectral ratios calculated by rotating the two horizontal components between $0^{\circ}$ and $180^{\circ}$, at steps of $10^{\circ}$. Consistently to Figure 5 there is a good agreement between all measurement points. Moreover, amplitudes are not affected by strong directional variations as different rotation angles show amplitudes of the two main peaks between a factor of 2 and 3. The FAS analysis of the three components of the ground motion (Figure 7) allows investigating in detail possible differences between measurement points. Spectra of the horizontal components (Figure 7 , left and middle panels) are very similar in shape for frequencies below $1 \mathrm{~Hz}$, with a sharp peak around $0.3 \mathrm{~Hz}$. On the East components the agreement is good for frequencies below $4 \mathrm{~Hz}$ with another peak at $2 \mathrm{~Hz}$. This latter peak is visible also for the North components but with higher variation among the measured points. FAS of horizontal components diverge significantly for frequencies above $4 \mathrm{~Hz}$. In particular, at the ST0 station outside the foundation the FAS shows a strong peak at $10 \mathrm{~Hz}$. Lower differences are observed at the other stations. The spectra of the vertical component show maxima in a large frequency band between 3 and $11 \mathrm{~Hz}$, with two peaks at about 4 and $10 \mathrm{~Hz}$ (Figure 7, right panel). Once again station ST0 is the only one showing significant increases in amplitude between 3 and $11 \mathrm{~Hz}$. The FAS of ST1 station shows amplitudes slightly larger than those of the other stations located on the foundation above $1 \mathrm{~Hz}$. This may be due to the proximity of ST1 to the underground tunnel and the data could be affected by the signals produced by railways.

Despite these differences in the spectra at the station outside the foundation (ST0) and the other stations on the foundation of the $\mathrm{AF}$, the $\mathrm{H} / \mathrm{V}$ analysis results in negligible variations. This means that the foundation acts as a filter on ground motion similarly for the three components of ground motion.

\section{$C-C$ configuration}

The Commodus Passage is not generally accessible to the tourists; therefore it was possible to leave the recording stations in operation for several hours, including the night-time. The $\mathrm{H} / \mathrm{V}$ and FAS analysis have been performed for both day (maximum of the anthropic activity) and night-time (minimum of the anthropic activity). The spectra were calculated using 120 minute long synchronous time windows during day-, between 6 and 8 PM, and night-time, between 2 and 4 AM, respectively.

Figure 8 shows the $\mathrm{H} / \mathrm{V}$ results, with almost identical shapes for the day- and night-time periods. The shape of $\mathrm{H} / \mathrm{V}$ spectral ratios is also very similar to the one calculated for the configuration C-B (compare Figures 6 and 8). As also observed for stations in configuration C-B, the FAS analysis highlights differences among measured points that do not lead to significant differences in $\mathrm{H} / \mathrm{V}$ spectral ratios (Figure 9). For configuration C-C we can study also the variation of FAS with the recording time.

During day-time, the behavior of the three FAS for stations from ST0 to ST05 is very similar to that observed for the stations installed on the foundation in configuration C-B (top panel of Figure 9). On the other hand, , the FAS of stations ST06 and ST07 (red and orange curves, Figure 9) diverge from the others and show a behavior similar to that of station ST0 installed in the hypogeum in configuration C-B. This observation confirms the hypothesis that these two stations are located outside the AF foundation.

Such day-time differences on FAS during daytime between stations on and outside the foundation are lower during night-time (Figure 9, bottom). Indeed, the FAS are quite flat for frequencies above 1 $\mathrm{Hz}$ and about 4 times lower than the ones observed 

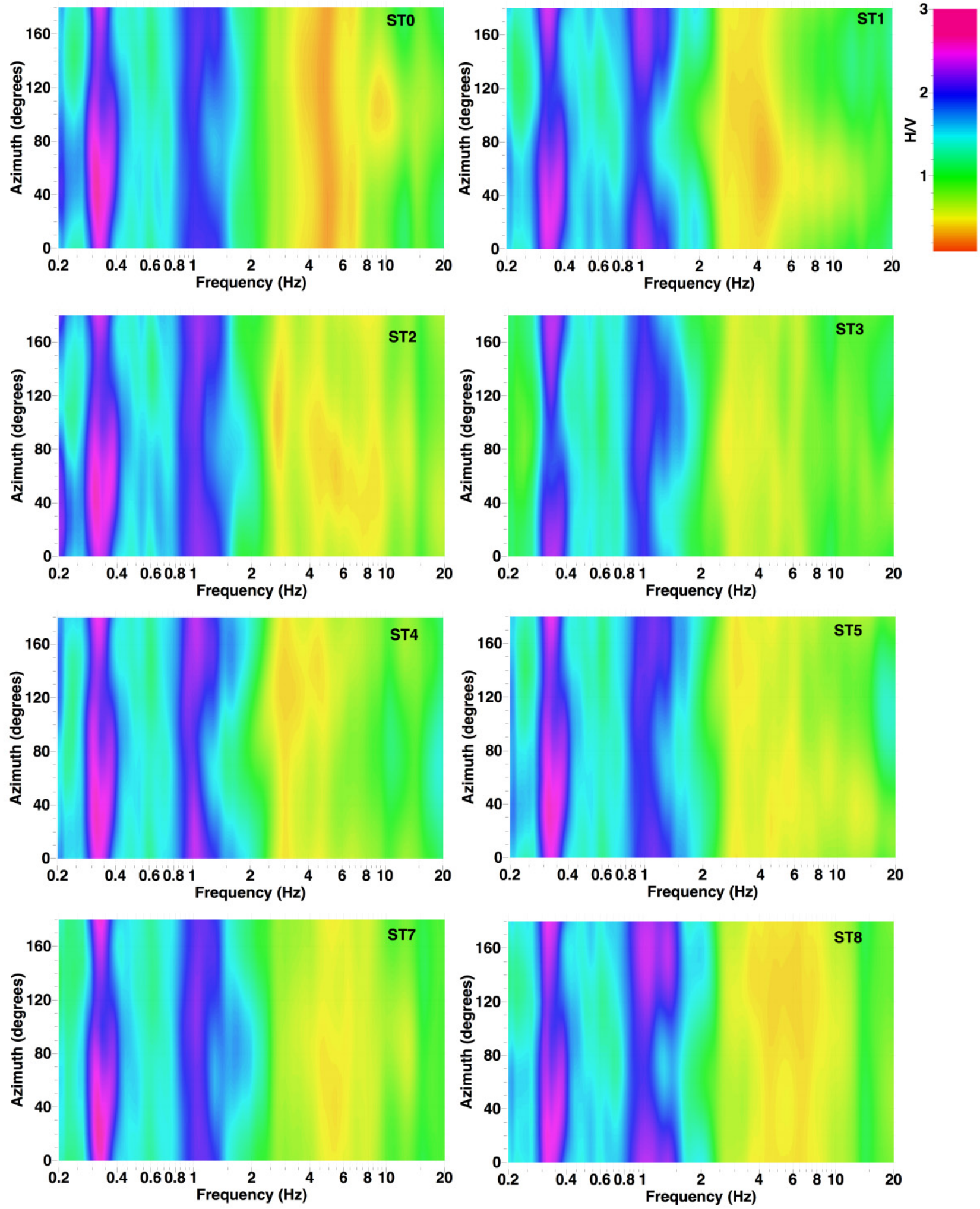

Figure 6. H/V spectral ratios at stations of the C-B configuration, calculated by rotating the two horizontal component of ground motion by steps of $10^{\circ}$, from 0 to $180^{\circ}$.

on day-time. This is a clear indication that the AMV of anthropic origin controls the energy distribution of the seismic noise above $1 \mathrm{~Hz}$, as expected [Bonnefoy-Claudet, Cotton and Bard 2006]. Anyway, the variations of FAS between the three components are always comparable therefore producing very similar $\mathrm{H} / \mathrm{V}$ spectral ratios.

\section{$C$-D configuration}

The C-D deployment is different from the previous, because only one station was placed on the foundation of the AF, whereas the other two were set on the first and second floors, respectively in correspondence of the "Fornix LV" close to the "Sperone Valadier". Such configuration can provide information about 


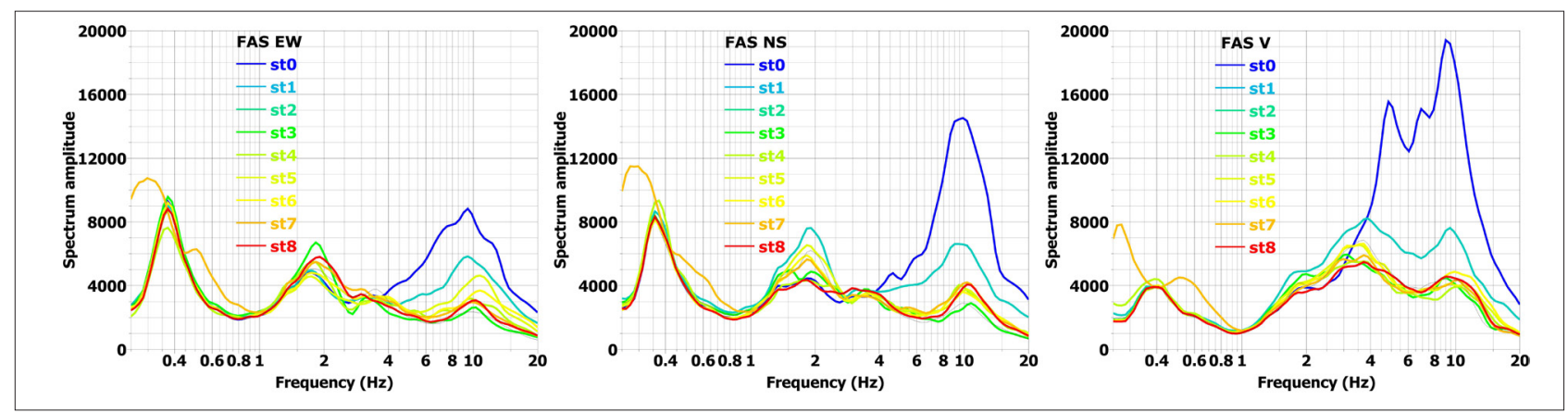

Figure 7. FAS of the east (left), north (middle) and vertical (right) components of motion recorded with C-B configuration.

ground motion variations from the bottom to the top of the structure. The duration of the simultaneous recordings (about 5 hours) ensures the statistical significance of the results.

Figure 10 shows the spectral ratios of the relative motion recorded at the second (L2) and first floor (L1) of the vertical array de-convoluted with respect to the ground motion obtained at the foundation (L0). These

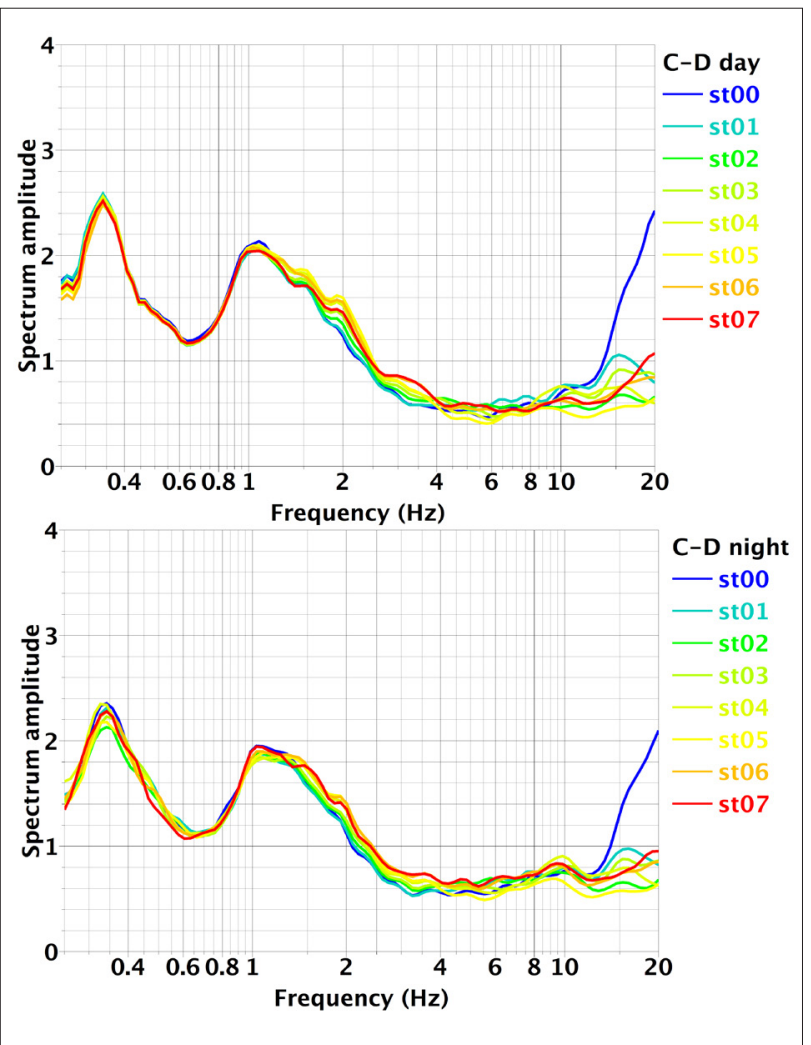

Figure 8. H/V spectral ratios calculated at the stations of C-D configurations, selecting data acquired during day (top panels) and night (bottom panels).

functions were calculated to clearly determine the vibration frequencies of the superstructure by removing the ground-borne ambient vibration input spectra at the base of the monument from those recorded at the upper levels. For each component of the recorded motion, radial, tangential and vertical, recorded at L2 and
L1 levels, the relative motion between the structure and the foundation was calculated as L2 (or L1) - L0 in the time domain and subsequently de-convoluted by L0 in the frequency domain. In this way, it is possible to retrieve the monument transfer function under the hypothesis of the monumental structure behaving as a linear system under low level of loading, such that induced by ambient vibrations. The spectral ratio functions were smoothed using a high $b$ value $[b=99$, low smoothing; Konno and Ohmachi 1998] to better distinguish between peaks at closely spaced frequencies.

For the radial component, the de-convoluted spectra show two clear peaks at about 1.3 and $2.7 \mathrm{~Hz}$ both at the L1 and L2 levels (Figure 10, left panel). Similarly, the spectral ratios of the vertical component at $\mathrm{L} 2$ and $\mathrm{L} 1$ show two main peaks again at $1.3 \mathrm{~Hz}$ and around $11 \mathrm{~Hz}$ (Figure 10, right panel), while the tangential spectral ratio functions have several peaks with comparable amplitude in the frequency range 1.3-15 Hz (Figure 10, central panel).

The amplitude of the functions displayed in Figure 10 shows that the prevalent motion of the structure is in the radial direction.

The $1.3 \mathrm{~Hz}$ spectral peak corresponds to the fundamental resonance frequency of the monumental building and is associated with a bending mode of the external monument wall in the radial direction [Pau and Vestroni 2008, Bongiovanni et al. 2017 - this issue].

The $2.7 \mathrm{~Hz}$ peak on the radial component have the highest amplitude among all the functions calculated at the same level. At L2 (Figure 10, top panel) the $2.7 \mathrm{~Hz}$ peak is the predominant peak both in the radial and tangential components. This frequency was identified by other authors and associated with a local mode of the Valadier's buttress [Bongiovanni et al. 2017 - this issue].

As several authors verified that $\mathrm{H} / \mathrm{V}$ method can be effectively used to characterize the dynamic behavior of buildings [Chavez-Garcia and Cardenas-Soto 2002, Gallipoli et al. 2004, Gallipoli et al. 2009], we also calculated the $\mathrm{H} / \mathrm{V}$ spectral ratios at the three levels 


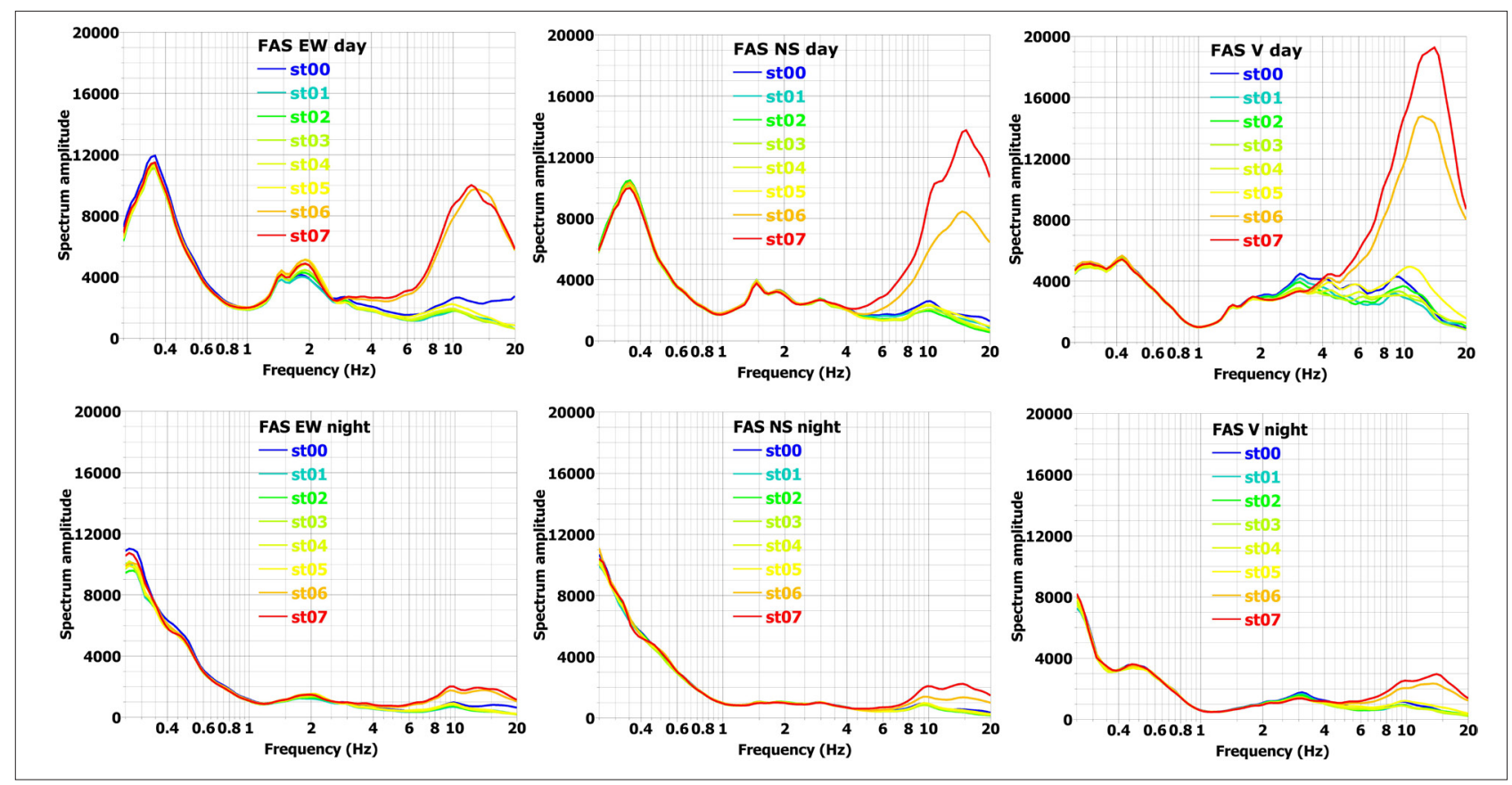

Figure 9. FAS of the east (left), north (middle) and vertical (right) components of motion recorded with C-D sensor configuration. The top and bottom panels show FAS calculated during day and night acquisitions, respectively.

L0, L1 and L2 (Figure 11) for comparison with the results obtained by the previous analysis.

In this case the spectral ratios were calculated by projecting the horizontal component of motion into 6 selected horizontal directions ranging from the radial through the tangential directions with respect to the AF map view and reaching the rotation of $150^{\circ}$ clockwise with respect to the radial direction. The final $\mathrm{H} / \mathrm{V}$ spectral ratios were smoothed as previously by using a high $\mathrm{b}$ value.

Despite this smoothing procedure, the $\mathrm{H} / \mathrm{V}$ calculated at the base L0 is very similar to those obtained for stations installed on the foundation in configurations C-B and C-C. The shape of L0 does not change significantly when rotating the horizontal components. The $\mathrm{H} / \mathrm{V}$ spectral ratios for the other two floors, L1 and L2, differ drastically from L0, and they are azimuth-dependent. The main peak is at about $2.7 \mathrm{~Hz}$, and its amplitude increases moving from L1 to L2. Moreover the effect of this peak is greater for the radial direction than for the tangential one. The other relevant peak is in the range 1.2-1.3 Hz. The directional analysis for L2 shows that moving from radial to tangential, this

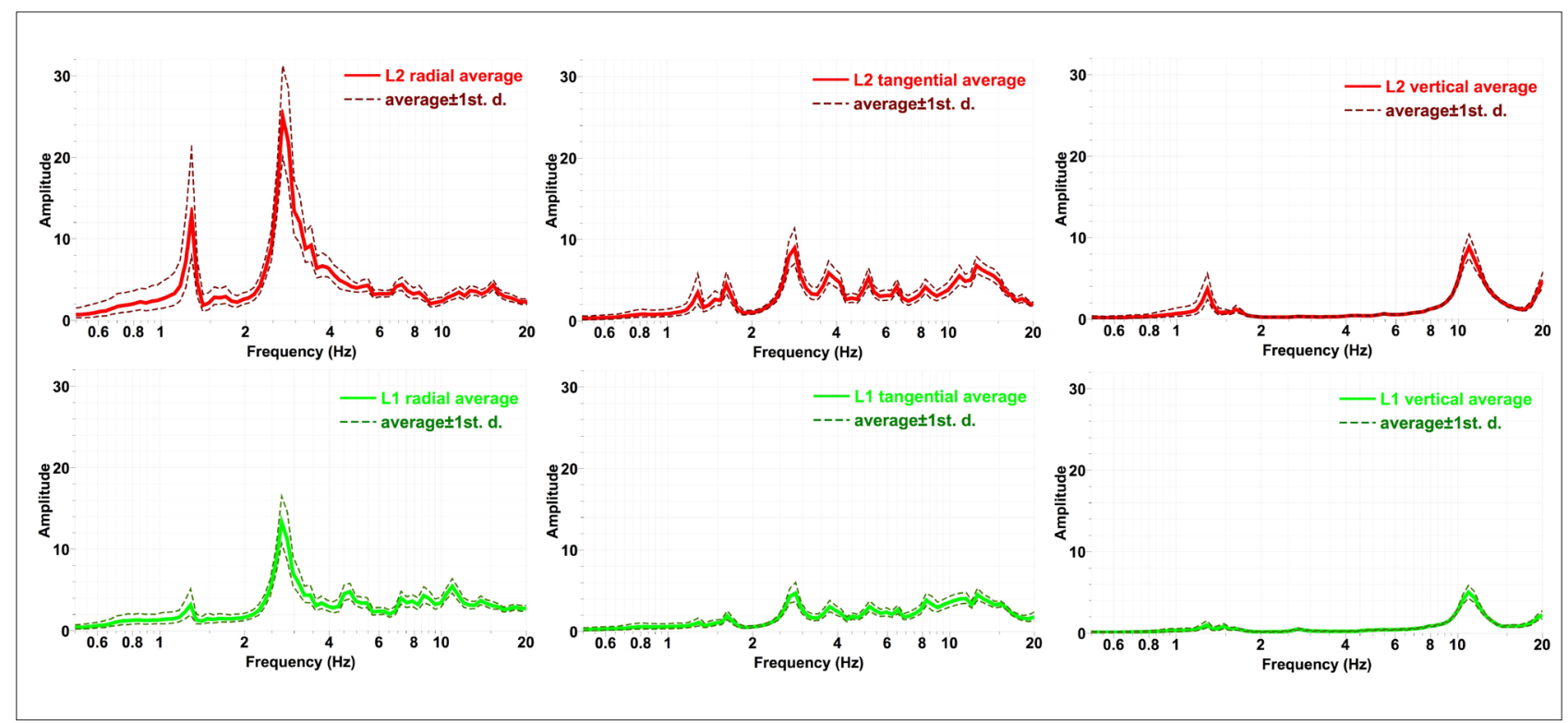

Figure 10. Spectral ratios of the relative motion recorded at the second (L2, top panel) and first floor (L1, bottom panel) of the vertical array de-convoluted with respect to the ground motion obtained at the foundation (L0) fore the Radial (left panels), Tangential central panels) and Vertical (right panels) components. 


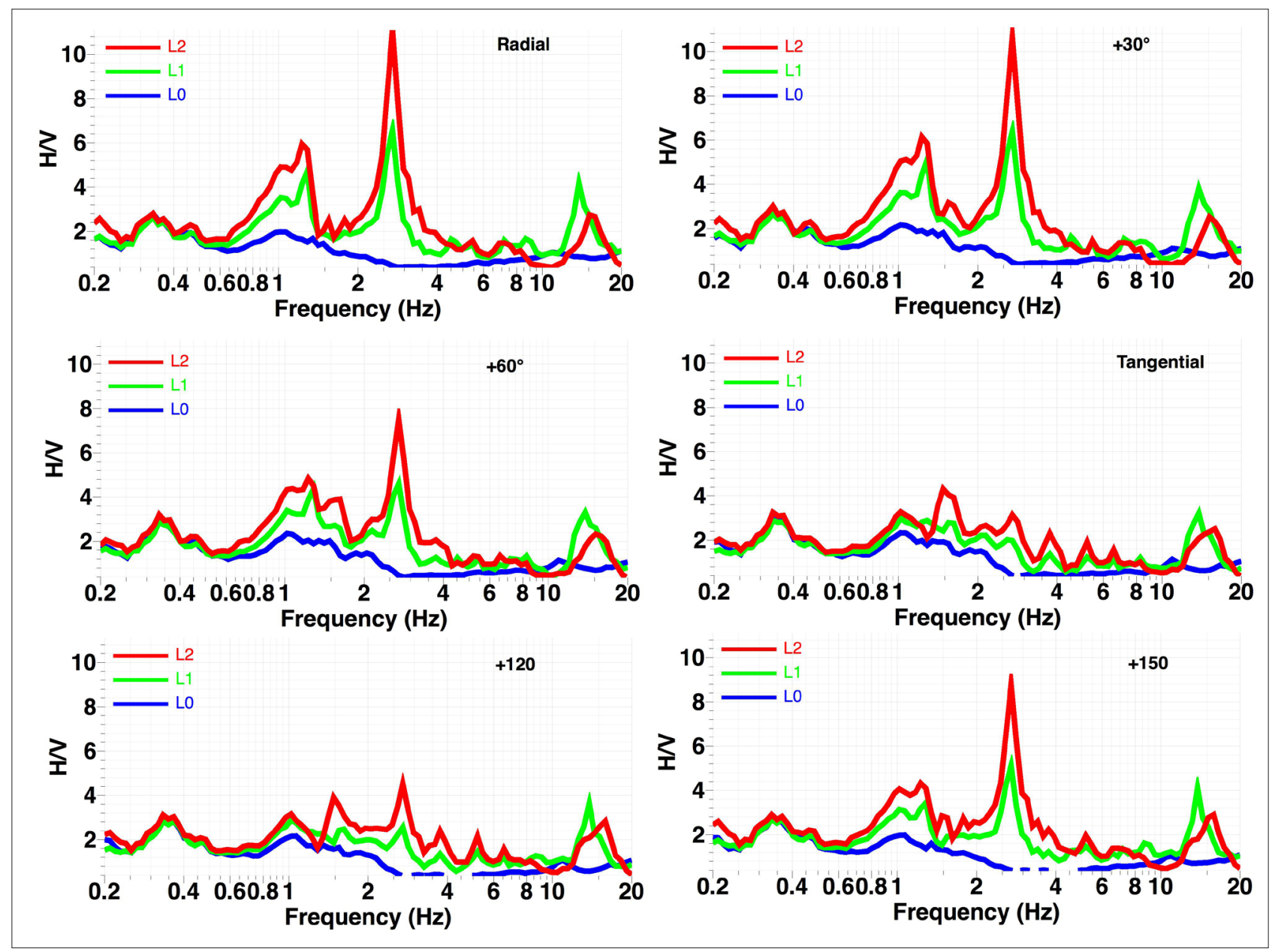

Figure 11. FAH/V spectral ratios calculated at the levels L0 (blue curve), L1 (green curve) and L2 (red curve) in the monumental structure. Each panel refers to a projection of the horizontal components along a specific direction between the radial $\left(0^{\circ}\right.$ rotation) through the tangential $\left(90^{\circ}\right.$ rotation) and to $150^{\circ}$ rotation before computation of the spectral ratio.

peak splits into two different peaks with lower amplitude at about $1 \mathrm{~Hz}$ and $1.5 \mathrm{~Hz}$. Further, along the tangential direction at $\mathrm{L} 2$ several peaks appear in the $2-8 \mathrm{~Hz}$ frequency range. We finally observe that $\mathrm{L} 1$ and L2 show two other not directional peaks at 12 and $15 \mathrm{~Hz}$, respectively, with amplitude independent of the azimuth and not present on L0.

From the comparison between the functions of Figure 10 and Figure 11 it is possible to observe that both methods are capable to identify the main resonance frequency of the monumental building at $1.3 \mathrm{~Hz}$ and the local mode of the Valadier's buttress at $2.7 \mathrm{~Hz}$. However the first method provided a better resolution of the resonance peaks with respect to the $\mathrm{H} / \mathrm{V}$ method.

To summarize, the resonance frequencies of the AF are mainly concentrated in the frequency band $1-4 \mathrm{~Hz}$ and in the radial direction. The motion at level 0 is not influenced by the monumental structure, suggesting that in this frequency range the observed peaks at 0.3 and $1 \mathrm{~Hz}$ are related to the subsurface structure.

\subsection{Vp-seismic tomography results}

The active seismic data were used for the reconstruction of a Vp tomographic image based on the inversion of the first arrival traveltimes. For the identification of the first arrival time, the acquired seismic traces were organized in Common Shot Gather (CSG) seismic sections. The picking of first arrivals was manually performed only on stacked traces in which the signal relating to first arrival shows an acceptable signal to noise ratio. A total number of 1395 picks were detected with a mean uncertainty of the order of $1 \mathrm{~ms}$.

The picked traveltimes are used as input data of a 2D tomographic inversion based on Simultaneous Iterative Reconstruction Technique [SIRT, Trampert and Leveque 1990] and using the ray paths calculated by a finite difference approximation of the Eikonal equation to solve the forward problem.

The final retrieved model is shown in Figure 12. The associated root mean square (RMS), calculated from the differences between the observed and computed traveltimes of $1 \mathrm{~ms}$, is comparable to the error of measurement of the traveltimes. The paths of the 


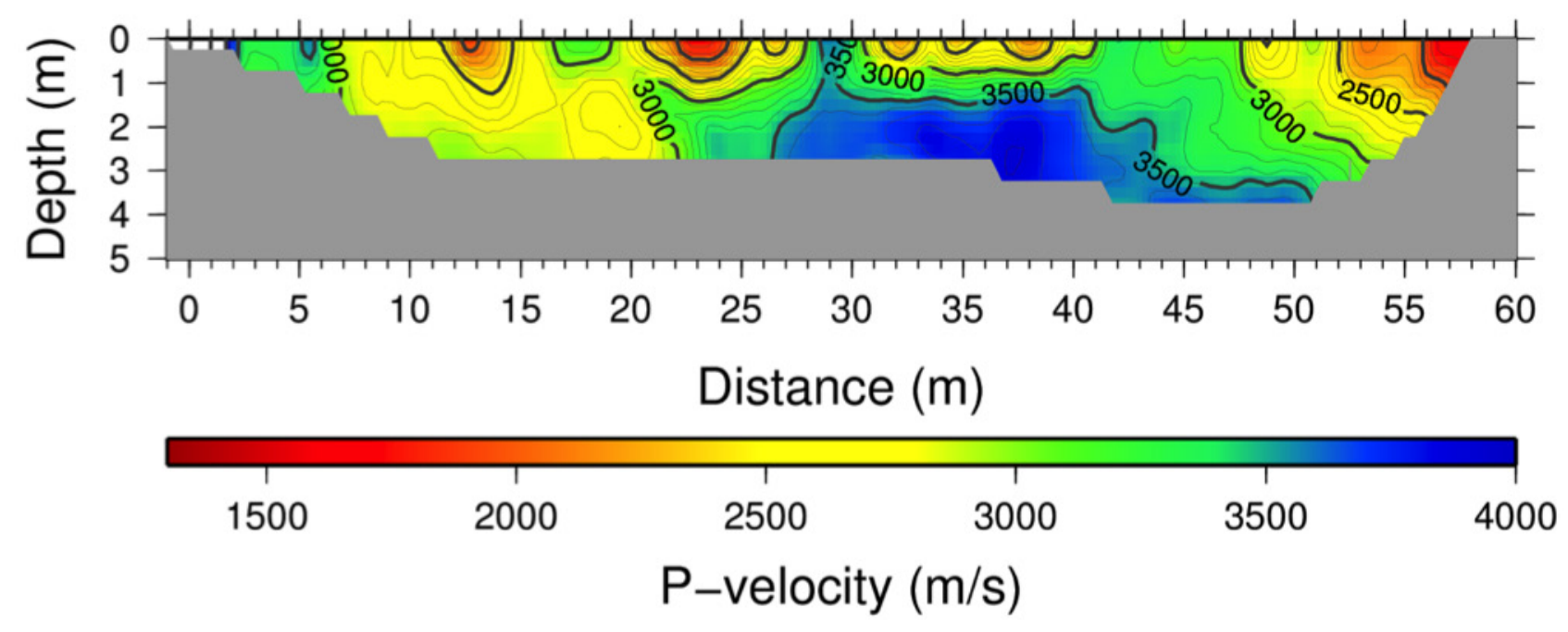

Figure 12. 2D tomographic model obtained by the seismic active data acquired along the Commodus Passage.

seismic rays are used to define the areas of $2 \mathrm{D}$ velocity model well-sampled by seismic waves. The maximum investigation depth reaches about $4 \mathrm{~m}$ below the final part of the acquisition line (between 42 and $51 \mathrm{~m}$ distance along the line, Figure 12). The retrieved velocity shows values between $2000 \mathrm{~m} / \mathrm{s}$ and $3500 \mathrm{~m} / \mathrm{s}$. Such high velocity values and the position of investigated area at the base of monument suggest that the material sampled by seismic waves is the roman concrete used for the foundation of Colosseum. In the shallowest part (up to $1 \mathrm{~m}$ of depth) of the model there are several low velocity areas (Vp around $2000 \mathrm{~m} / \mathrm{s}$ ) with lateral dimensions of a few meters. These small anomalies are probably related to the deterioration of the material used for the foundation of monument.

\section{Discussion and conclusions}

The results obtained by the $\mathrm{H} / \mathrm{V}$ spectral ratio and FAS analyses lead to some consideration about the response of the AF's foundation and structure. The H/V spectral ratios of AVM at different points of the foundation and immediately outside (hypogeum or the two last points of the Commodus Passage) remain constant in shape and amplitude. Even considering different levels of AMV excitation (during day and night-time), the $\mathrm{H} / \mathrm{V}$ is always stable regardless of the positions of the measuring instruments. As the shape of the $\mathrm{H} / \mathrm{V}$ reflects the local subsurface shear-wave velocity structure, this observation suggests that no significant differences are present in the local subsurface structure between the measuring points.

Previous studies [Moczo et al. 1995] based on numerical simulation of seismic wave propagation predicted higher amplitude ground-motion levels in the south-eastern sector than in the north-western one of the AF. Funiciello and Rovelli [1998] hypothesized that the collapse of the South external wall of the AF during centuries is due to a higher amplification of earthquake ground-motion in the south-eastern sector of the monument. Our results in terms of $\mathrm{H} / \mathrm{V}$ seem to confute this hypothesis as we observed a strong similarity between the North and South sector of the AF. One possible reason for this discrepancy is the sub-surface velocity structure used by Moczo et al. [1995]. These authors assumed a Vs of $800 \mathrm{~m} / \mathrm{s}$ for the MVA and Vs between 100 and $200 \mathrm{~m} / \mathrm{s}$ for the alluvia of the Labicano valley in the $S$ sector of the AF. In the light of the new available data about the dynamic characterization of soils in the Central Archeological area of Rome [Pagliaroli et al. 2014b, Cardarelli et al. 2017 - this issue], this high impedance contrast seems to be unrealistic.

Despite the similarity of the H/V curves calculated on and outside the foundation, our results showed significant variations in the amplitude spectral level between AMV measures on the foundation and at the hypogeum. In particular, our observations highlight that the foundation has a positive effect on the spectral content of the ground motion, strongly attenuating the amplitudes of frequencies above $4 \mathrm{~Hz}$, i.e. the frequency range mostly originated by traffic vibrations. This effect is likely due to the high seismic velocities of the foundation materials as proved by our seismic tomography results ( $\mathrm{Vp}$ above $3500 \mathrm{~m} / \mathrm{s})$. The role of the rigid foundation shall be also taken into account when assessing the seismic vulnerability of the monumental structure.

The H/V peaks of configuration C-D, suggest that the vibrations of the structure do not affect the motion at its base. Indeed the H/V analysis performed 
rotating the horizontal components indicates that the structure does not produce directional effects, therefore two $\mathrm{H} / \mathrm{V}$ peaks around 0.3 and $1 \mathrm{~Hz}$ observed at the ground level can be related to the sub-surface conditions. The amplitude level of the two peaks is relatively low, never exceeding a factor of 2.5. Even if the amplitude is not considered a reliable indication of an amplification effect [Bard and SESAME Team 2005], it is however an indication of the impedance contrasts between the sub-surface layers and the supposed seismic bedrock. Therefore, the two peaks at $0.3 \mathrm{~Hz}$ and around $1 \mathrm{~Hz}$ are in principle related to low-to-moderate impedance contrasts at very different depths: the former is likely due to a resonant interface at depths in the order of several hundred meters; the latter could be related to a shallower resonant interface. However the peak around $1 \mathrm{~Hz}$ does not fit the available geological and geophysical information. In fact, if we consider up to $30-40 \mathrm{~m}$ of alluvial and recent sediments (Vs roughly around $250 \mathrm{~m} / \mathrm{s}$ ) overlying the MVA unit (Vs roughly $600 \mathrm{~m} / \mathrm{s}$ ) or $20-30 \mathrm{~m}$ of fine alluvial sediments of the SFTba3 (Vs of $250 \mathrm{~m} / \mathrm{s}$ ) overlying the stiff gravel of the SFTba1 unit (Vs of $700 \mathrm{~m} / \mathrm{s}$ ), the resonant frequency should be grater than $2 \mathrm{~Hz}$. Thus, we hypothesize that the origin of the peak around $1 \mathrm{~Hz}$ is related to the resonance of the close Tiber valley. In fact, several AMV measurements in different part of Rome show a persistent $\mathrm{H} / \mathrm{V}$ peak at $1 \mathrm{~Hz}$, which supports this hypothesis (Carlucci $\mathrm{PhD}$ thesis in preparation).

Looking at the results obtained from the spectral analysis of the signals recorded at different heights in the AF (Figures 10 and 11), we obtained strong peaks with amplitude dependent on the considered horizontal direction. This behavior can be related to differential motions of the structure. In particular, we experimentally showed that spectral ratios of the relative motion recorded at the second (L2) and first floor (L1) deconvoluted with respect to the ground motion obtained at the foundation ( $\mathrm{L} 0$ ) and $\mathrm{H} / \mathrm{V}$ calculated at $\mathrm{L} 1$ and L2 provide consistent estimate of the resonance frequencies of the AF which are mainly related to the radial motion of the structure. Along the radial direction, at the first and second floor both methods show frequency peaks around 1.3 and $2.7 \mathrm{~Hz}$. The former is a clear resonance frequency of the building and the latter is a local mode of the Valadier's buttress. In detail, as these peaks are related to radial resonances, their amplitude decrease when the $\mathrm{H} / \mathrm{V}$ is calculated along the tangential direction, for the other peaks, a more complex behavior has been observed as a function of the azimuth in the $\mathrm{H} / \mathrm{V}$ functions.
The main resonance frequency of the structure is about $1.3 \mathrm{~Hz}$ [Pau and Vestroni 2008, Clemente et al. 2015]. Due to its closeness with the resonance frequency of the ground (about $1 \mathrm{~Hz}$ ), we believe that important site-structure interactions cannot be excluded in case of strong earthquakes. Therefore, these soil-structure interactions have to be taken into account when modeling the AF seismic response.

\section{References}

Bard, P.Y. and SESAME Team (2005). Report D23.12, Guidelines for the implementation of the H/V spectral ratio technique on ambient vibrations measurements, processing and interpretation, in European Commission: Research General Directorate, Project No. EVG1-CT-2000-00026, SESAME, 62 pp.: available online at http:// sesame.geopsy.org/Delivrables / Del-D23-HV_User_ Guidelines.pdf (last accessed April 2017).

Bongiovanni, G., G. Buffarini, P. Clemente, D. Rinaldis and F. Saitta (2017). Dynamic characteristics of the Amphiteatrum Flavium northern wall from traffic-induced vibrations. Annals of Geophysics, 60, Special Issue "Monitoring and seismic characterization of archaeological sites and structures", doi: $10.4401 /$ ag-7178.

Bonilla, F., F. Bozzano, C. Gelis, AC. Giacomi, L. Lenti, S. Martino, MP. Santisi D'Avila and JF. Semblat (2011). Numerical modelling of shaking effects due to strong motions on the Tiber alluvial deposits in Rome (Italy). In: Proceedings of "effects of suface geology on seismic motion". University of California Santa Barbara.

Bonnefoy-Claudet, S., F. Cotton and P.Y. Bard (2006). The nature of the seismic noise wave field and its implication for site effects studies: a literature review, Earth Sci. Rev., 79, 205-227.

Bozzano, F., A. Andreucci, M. Gaeta and R. Salucci (2000). A geological model of the buried Tiber River valley beneath the historical centre of Rome, Bull. Eng. Geol. Environ 59:1-21.

Bozzano, F., R. Funiciello, F. Marra, A. Rovelli and G. Valentini (1995). Il sottosuolo dell'area dell'Anfiteatro Flavio in Roma, Geologia Applicata e Idrogeologia 30(1):405-422.

Cardarelli, E., M. Cercato and L. Orlando (2017). Geometry and seismic characterization of the subsoil below the Colosseum (Amphitheatrum Flavium), Rome. Annals of Geophysics, 60, Special Issue "Monitoring and seismic characterization of archaeological sites and structures”, doi: 10.4401/ag-7174. 
Chavez-Garcia, FJ., Cardenas-Soto, M. (2002). The contribution of the built environment to the 'free-field' ground motion in Mexico city. Soil Dynamics and Earthquake Engineering, 22:773-780.

Ciotoli, G., F. Stigliano, F. Marconi, M. Moscatelli, M. Mancini and GP. Cavinato (2011). Mapping the anthropic backfill of the historical center of Rome (Italy) by using Intrinsic Random Functions of order k (IRF-K). In: Murgante B, Gervasi O, Iglesias A, Taniar D, Apoluhan BO (eds) Computational Sciences and its applications. ICCSA 2011 Part I, Proceedings of the 11 th international conference, Santander,. June 20-23 2011, Lecture notes in computer science, 6782, Springer, Berlin, pp 92-102.

Facke, A., Parolai S., Richwalski S. and Stempniewski L. (2006). Assessing the vibrational frequencies of the Cathedral of Cologne (Germany) by means of ambient seismic noise analysis, Natural Hazards 38, 229-236.

Funiciello, R. and G. Giordano (2008). Note illustrative della Carta Geologica d'Italia alla scala 1:50.000, Foglio 347 Roma. APAT-Servizio Geologico d'Italia, Roma.

Funiciello, R. and A. Rovelli (1998), Terremoti e monumenti a Roma, Le Scienze, maggio.

Funiciello, R., L. Lombardi, F. Marra and M. Parotto (1995). Seismic damage and geological heterogeneity in Rome's Colosseum area: Are they related?, Ann. Geofis. 38:927-937.

Funiciello, R. and M. Parotto (1978). Il substrato sedimentario nell'area dei Colli Albani: considerazioni geodinamiche e paleogeografiche sul margine tirrenico dell'Appennino central, Geol. Romana 17:233-287.

Galli, P.A.C. and D. Molin (2014). Beyond the damage threshold: the historic earthquakes of Rome, Bull. Earthquake Eng. 12: 1277.

Gallipoli, M.R., M. Mucciarelli, R.R. Castro, G. Monachesi and P. Contri (2004). Structure, soil-structure response and effects of damage based on observations of horizontal-vertical spectral ratios of microtremors. Soil Dynamics and Earthquake Engineering 24, 487-495.

Gallipoli, M.R., M. Mucciarelli, and M. Vona (2009). Empirical estimate of fundamental frequencies and damping for Italian buildings. Earthquake Engineering and Structural Dynamics, 38: 973-988.

Giordano, G. and R. Mazza (2010). The Geology of Rome and urban areas: the legacy of Prof. Renato Funiciello. In: Beltrando M, Peccerillo A, Mattei M, Conticelli S, Doglioni C (eds) The geology of Italy; tectonics and life along plate margins. J. Virtual Exp. 36, paper 28. doi:10.3809/jvirtex.2010.00277.

Konno, K. and T. Ohmachi (1998). Ground-motion characteristics estimated from spectral ratio between horizontal and vertical components of microtremors, Bulletin of the Seismological Society of America, 88, 228-241.

Lanciani, R. (1897). The ruins and excavations of ancient Rome. A companion book for students and travellers. Houghton Mifflin company, The Riverside Press Cambridge, Boston and New York, p 619.

Mancini, M., M. Marini, M. Moscatelli, A. Pagliaroli, F. Stigliano, C. Di Salvo, M. Simionato, GP. Cavinato and A. Corazza (2014). A physical stratigraphy model for seismic microzonation of the Central Archaeological Area of Rome (Italy), Bull. Earthquake Eng. 12: 1339, pp 1339-1363. doi:10.1007/s10518-014-9584-2.

Marra, F., F. Florindo and E. Boschi (2008). History of glacial terminations from the Tiber River, Rome: insights into glacial forcing mechanisms, Paleoceanography 23, PA2205. doi:10.1029/2007PA001543.

Michel, C., Gueguen P. and Bard P-Y. (2007). Dynamic parameters of structures extracted from ambient vibration measurements: An aid for the seismic vulnerability assessment of existing buildings in moderate seismic hazard regions, Soil Dynamics and Earthquake Engineering, doi: 10.1016/j. soildyn.2007.10.002.

Milli, S. (1997). Depositional setting and high-frequency sequence stratigraphy of the Middle-Upper Pleistocene to Holocene deposits of the Roman Basin, Geol. Romana 33:99-136.

Moczo, P., A. Rovelli, P. Labák, and L. Malagnini (1995). Seismic response of the geologic structure underlying Roman Colosseum and a 2D resonance of a sediment valley, Ann. Geofisc. 38, no. 5- 6, 939-956.

Molin, D., S. Castenetto, E. Di Loreto, E. Guidoboni, L. Liperi, B. Narcisi, A. Paciello, F. Riguzzi, A. Rossi, A. Tertulliani and G. Traina (1995). Sismicita ', in Mem. Descr. a Carta Geol. Ital. La Geologia di Roma Il centro storico, R. Funiciello (Editor), 50, 323-408.

Nakamura, Y. (2000). Clear identification of fundamental idea of Nakamura's technique and its applications, in 12th World Conf. on Earthquake Engineering, Auckland, New Zealand.

Nogoshi, M. and T. Igarashi (1971). On the amplitude characteristics of microtremor (part 2), J. 
Seismol. Soc. Japan, 24, 24-60, (in Japanese with English abstract).

Orlando, L., G. De Donno, L. Di Giambattista and L. Palladini (2017). Investigating the foundation of the Colosseum thorough the Passage of Commodus. Annals of Geophysics, 60, Special Issue "Monitoring and seismic characterization of archaeological sites and structures", doi: 10.4401/ag-7183.

Pagliaroli, A., B. Quadrio, G. Lanzo and T. Sanò (2014a). Numerical modelling of site effects in the Palatine Hill, Roman Forum, and Coliseum Archaeological Area, Bull. Earthquake Eng. 12:1383-1403.

Pagliaroli, A., G. Lanzo, P. Tommasi and V. Di Fiore (2014b). Dynamic characterization of soils and soft rocks of the Central Archaeological Area of Rome, Bull. Earthquake Eng. 12:1365-1381.

Pau, A. and F. Vestroni (2008). Vibration analysis and dynamic characterization of the Colosseum, Struct. Control Health Monit., 15: 1105-1121. doi:10.1002/stc. 253 .

Raspa G., M. Moscatelli, F. Stigliano, A. Patera, F. Marconi, D. Folle, R. Vallone, M. Mancini, GP. Cavinato and S. Milli (2008). Geotechnical characterization of the upper Pleistocene-Holocene alluvial deposits of Roma (Italy) by means of multivariate geostatistics: Cross-validation results, Eng. Geol. 101:251-268.

Rea, R., H.-J. Beste and L.C. Lancaster (2002). Il cantiere del Colosseo, Römische Mitteilungen 109: 341-375.

Rovelli, A., A.Caserta, L. Malagnini and F. Marra (1994). Assessment of potential strong ground motion in the city of Rome, Ann. Geofis. 37(6):1745-1769.

SSBA, http://archeoroma.beniculturali.it/sites/default/files/brochure_colosseo_UK.pdf.

Trampert, J., and J.-J., Leveque (1990). Simultaneous iterative reconstruction technique: Physical interpretation based on the generalized least squares solution, J. Geophys. Res., 95(B8), 12553-12559, doi:10.1029/JB095iB08p12553.

Wathelet, M. (2005). Array recordings of ambient vibrations: surface-wave inversion, Ph.D. thesis, Liège University (Belgium).

${ }^{*}$ Corresponding author: Salomon Hailemikael

Communications Agenzia nazionale per le nuove tecnologie,

l'energia e lo sviluppo economico sostenibile, C.R. Casaccia,

Via Anguillarese, 301, Rome, Italy;

email: salomon.hailemikael@enea.it

2017 by Istituto Nazionale di Geofisica e Vulcanologia.

All rights reserved 